\title{
SPIRITUALITY IN PEDAGOGY: A QUALITATIVE STUDY WITH EDUCATORS
}

\section{Raisuyah Bhagwan}

\section{INTRODUCTION}

The global momentum surrounding spirituality has increased in the West. An empirical base has evolved over the past two decades which supports the inclusion of spirituality in education. Research with students, practitioners and educators reflects a historically dominant silence in the field, which catalysed arguments for its inclusion in America curricula. Despite these emerging pathways, spirituality has remained distant from social work in South Africa (Bhagwan, 2002).

In one of a few enquiries in this field locally Bhagwan (2010) found through a survey with final-year social work students that a majority had a positive view of spirituality in practice, $87 \%$ reported receiving no or scant information on spirituality during their training, $45 \%$ voted in favour of spirituality being offered as a required course and $34 \%$ as an elective. This finding, coupled with the burgeoning empirical and conceptual papers that exemplify its synchrony with a range of practice issues (Canda, 2005), clearly indicated a need to open conversations with local academics about its location in education. Issues related to the incorporation of spirituality in education, focal content areas on spirituality, and whether and how to introduce it into pedagogical processes need to be probed with academics to shed light on spirituality's position in the local landscape. Hence the objectives of this inquiry was to deepen an understanding of educators' views about and experiences of spirituality at a personal level, in practice and in pedagogical processes. The following section explains the methodology.

\section{RESEARCH METHODOLOGY}

\section{Paradigm for inquiry}

This study was shaped by the qualitative paradigm which stems from an anti-positivistic, interpretative approach that is holistic in nature and that elicits participant accounts of meaning, experience or perceptions, thereby providing rich descriptive data in the participants' spoken words (Fouché \& Delport, 2005). The specific tradition of inquiry selected was grounded theory, as the aim of the study was to uncover novel knowledge and to heighten understanding in an area in which empirical work and knowledge are almost absent in South Africa. Because the focus of the study was spirituality, a qualitative approach was deemed appropriate to explore the subjective understanding of participants' spiritual beliefs and their salience in pedagogy. Thus, although a survey was conducted with academics nationally, it was believed that the study of spirituality in social work education would be incomplete without a qualitative exploration of educators' perceptions, views and experiences of spirituality. This qualitative approach enabled transpersonal research methods to be used as the latter are most suited to inquiries that are spiritual in nature and which allow for a deeper exploration of the multidimensional facets of spirituality. Transpersonal research approaches allow for storytelling, intuition, emotion, creative expression and reflective listening as possible strategies and procedures to explore the spiritual or transpersonal in research (Braud \& Anderson, 1998). 


\section{Data collection and analysis}

The survey included an invitation to participate in the qualitative phase of this study. The survey was electronically mailed to Heads of Schools of Social Work, requesting their assistance to distribute it to all full-time/contract staff. Those who indicated a willingness to be interviewed were contacted and visits were made to universities to conduct interviews. Seventeen interviews were held with three males and 14 females. One focus group was also held with four educators, with one male and three females in this group. Six Schools of Social Work participated in this study. Interviews and the group discussion lasted approximately one and a half hours.

A semi-structured interview guide was used, which focused on the participants' personal experiences and conceptualisations of spirituality, their thoughts about its salience in practice and their views with regard to incorporating spirituality in pedagogy. The interviews and the group discussion were tape-recorded and then transcribed. There is no single correct method of using grounded theory (Dey, 1999) as grounded theory is generally "discovered, developed, and provisionally verified through systematic data collection and the analysis of data pertaining to that phenomenon" (Strauss \& Corbin, 1990:392). With this approach the researcher does not prove a theory, but "begins with an area of study and what is relevant to that area is gradually allowed to emerge". As in the current study, data are collected by means of interviews with multiple individuals who have participated in a process about a central phenomenon to "saturate categories" and construct a theory (Fouché, 2005:270).

The categories that emerged in analysis occurred inductively, allowing the researcher to ground these categories within the data from which they were derived. Berg (2007) affirmed that analytic categories are developed by sorting the themes or category labels from the data. Analytic categories emerge from the literature as well as the research questions and directly from interview questions. In this study the interview questions formed the primary analytical categories. Links between the categories and themes were then made as a way of enabling conceptual ordering of the mass of data. This allows for the essence of the story to be explicated. In the following sections this story is told, beginning with how educators experience spirituality and their personal conceptualisations of spirituality. The central thread of spirituality as being important to practice and education is then followed within the context of the challenges and fears or anxieties of educators about what to teach, how best to interweave spirituality into pedagogy and the teaching methodologies best suited to spirituality.

\section{DISCUSSION OF FINDINGS}

\section{Personal spirituality}

Participants were asked about their personal experience of spirituality. As is evident in the discussion that follows, some linked it to their personal life, whilst others linked it to their pedagogical role. A few educators $(\mathrm{N}=3)$ saw spirituality as embedded in religion and believed that spirituality flowed from religious norms and values. They described their daily experiences of spirituality as "the way you exercise your religion" and through a connection with God. A majority of the sample, however, indicated a broader and more holistic understanding of spirituality as an experience beyond the confines of religion. Echoing the sentiments of most educators, one said "I do not believe much in the dogma of religion. I have reverence for nature, the changing seasons, beauty in the environment around. I appreciate the linking of spirituality with social justice and this is where I make the connection with social work". Their daily experiences of spirituality appeared nestled within an interconnectedness with others and 
nature, e.g. "I experience it in the way I relate to people; I experience it when I look out at the mountains ..., my children sleeping ... spirituality is not connected to a particular God" or through "love for others and being compassionate". It is when "in a moment of sparkle I feel the divine presence, when I know I am being most creative, when I experience that connection with all that lives..."

Research analysis revealed that the terms "transcendent", "divine", "holistic", "wholeness" and "balance" were the primary descriptors in educators' conceptualisations. These resonate with conceptualisations of spirituality in social work literature (Carroll, 2001). For example, one educator said "I believe in a transcendental power and ... tap into it". Six participants shared personal stories of trauma related to cancer, infidelity, infertility and physical illness, referring to spirituality as their wellsprings of healing during difficult journeys. Half of the sample linked their spirituality with their pedagogical roles, saying that "I find my spirituality at times in a quiet space ... in my work and through a sense of balance". "Spirituality allows me to nurture my students ... my skills, my knowledge, my talents and when I am serving the universe is best when I am infusing my life's work with the divine ... so when I am with the students in the classroom, I know with mindfulness and the sense that we are one". Another said that spirituality is "the divine that you would bring into everything whether you were educating ... working with clients, not necessarily discussing it with the client or with anyone, but your sense of the divine as it intervenes with your life". Bullis (1996) conceived of it along similar lines, saying that it was inner feelings and experiences of the immediacy of a divine or transcendental power, whilst Canda and Furman (1999) described spirituality as a developmental process which embraced movement toward a sense of wholeness in oneself and others.

The current schism between spirituality and social work in South Africa may relate to the views of the three participants who said that they grappled with the difference between religion and spirituality. In the words of one educator, "Dogma clouds spirituality ... fundamentalist beliefs are often associated with religion." That spirituality and religion are not entirely in a dichotomous relationship may be a factor for the absence of spirituality in social work pedagogy in South Africa. Social work principles are antithetical to fundamentalist views and therefore concerns related to the negative aspects of religion (Loewenberg, 1988) may have stymied the interweaving of spirituality into pedagogy. Canda (2008) pointed out that religious ideologies are often used to rationalise violence, war, genocide or encourage harsh, demeaning and moralistic behaviour. One educator's suggestion of the need for "a shift in understanding", which separates spiritually sensitive practice from the dysfunctional elements of religion is critical to allowing a transcendence of thought with regard to spirituality's position in South African social work. In fact it was only after a strong articulation of this delineation that it emerged in American education (Amato-von-Hemert, 1994).

\section{Spirituality in practice}

Three broad themes emerged as rationales for the consideration of spirituality in practice. Diversity was identified by many participants as a rationale. Capturing the views of this group, one participant said that "we do not focus on the role of spirituality in relation to the diverse cultures we are dealing with". Whilst current South African pedagogy embraces cultural diversity, spirituality - as manifested within cultures - appears invisible. One participant articulated the need for African spirituality to be accorded a stronger voice, saying that because it underpins the lives of so many in South Africa, a greater understanding of it is critical to working effectively with clients with this worldview. Bhagwan (2002) supported this saying 
that an understanding of spiritually grounded interventions that embrace traditional healing practices are important in working with this group, as more of the local population have moved towards using indigenous therapies in times of crisis. Spiritual diversity, however, is not constrained to religious and cultural exploration, but includes elements of the diversity of gender and sexual orientation that need to be reflected in education as well (Bhagwan, 2002). Three participants proposed the blending of spirituality with current discussions on feminist worldviews. This stance has been supported by Canda and Furman (1999), who argued that feminist spiritual traditions have the potential to affirm women's experience and honour female aspects of the divine.

The second rationale revolves around spirituality as an integral component of the holistic perspective. Educators who made this point said that "spirituality cannot be disconnected from practice", "we teach the holistic perspective to students ... we need to consider a client's particular spirituality". Faver (1986) concurs, saying that social work has long subscribed to a holistic framework which posits that the biopsychosocial-spiritual and environmental factors are inseparable. Practitioners who neglect the spiritual dimension are therefore working antithetically to this framework and will miss opportunities for a complete assessment and treatment plan (Bhagwan, 2007; Derezotes, 2006).

To prepare students, educators will have to begin building a framework for spirituality into the curriculum (Cowley \& Derezotes, 1994). As one participant said, we "should not detract from the fact that the person has a spiritual essence", especially when dealing with "people who are traumatized, people experiencing grief, loss and pain". Another argued that "we never ask our clients about the spiritual dimension in assessment ... we don't know if they go to church or synagogue ... we don't ask about what meaning that has for them, we are not interested in that and I think it is an omission". Tolliver (1997) concurs on the need for social workers' awareness of the salience of the systems, practices, rituals and symbols which are embedded in a client's spiritual framework as an important aspect of assessment. Recently Bhagwan (2007) elaborated on the tools for spiritual assessment and intervention, and emphasized the importance of this in the educational preparedness of students.

The third rationale emanated from educators' spirituality as a source of strength. Most of the sample saw the link between spirituality and healing in the areas of violence, trauma, bereavement, depression and loss. One participant stated that it is "in these areas there is greater scope to ask people about the meaning and purpose of life". Canda (2008) affirmed this, stating that reflecting on death, on what happens (if anything) after death and dealing with the loss of loved ones evokes deep existential questions, issues of faith, meaning and soul searching. Even clients' spiritual beliefs and practices, as they interface and enable coping with violence, abuse, mental health and family dysfunction, are colouring the social work literature (Derezotes, 2006) and form valuable points for inclusion in education.

\section{Spirituality in pedagogy}

Almost the entire sample concurred that spirituality was important in pedagogy on the basis of the aforementioned rationales. Only two educators were adamant that spirituality was not relevant to social work. One said: "No, I think it is extraneous. It is part of someone's life ... I would not include it in training. Spirituality serves as a personal resource ... not as a professional resource; if they would use it would be up to them. I would not include it in the curriculum." This argument however, is contradictory, as social work seeks to tap into a client's personal strengths during healing (Saleebey, 1997). 
When asked whether spirituality had a presence in current pedagogical processes, most educators agreed it did, but that it was superficial. This ties up with findings made from the student survey (Bhagwan, 2010), where almost half the sample expressed the view that spirituality was rarely covered in education. According to participants in the current study, spirituality was mentioned minimally during the context of teaching other content. One educator said aspects such as "nature retreats, meditation, mindful reflective togetherness" are being spoken about in class, but not necessarily under the umbrella of spirituality. Most educators connected it with cultural diversity, which explains the strong support for the diversity rationale. Two other participants reflected that spirituality emerged during "classroom experience". One cited the following example, where a student involved in a group for rape survivors indicated that she had prayed for a survivor: "I also told her to go to the minister so he could pray for her." This then led to a discussion on imposing beliefs and ethical issues. "I asked: did this young person directly ask you to pray for her and we then unpacked this." She added "I had a case study at another session ... a terminally ill patient in hospital asks you to pray for her. I then asked students to discuss the issues involved in this, i.e. the intersection of ethics, morals and being in the moment with a client. I then asked students to role play what they would do after considering these dynamics.... what do you do when somebody who is a Hindu asks "Will you say a prayer for me?" I would respond by saying: Firstly I need to understand what you are requesting? How do I do this? I am not sure how you would best want me to do this, so I would rather not, but if you wish to pray I am here. But I would not say: I can pray for you." It is therefore important during teaching to include scenarios that may unveil themselves in practice.

For others spirituality influenced the pedagogical role personally. One participant said, "I link spirituality to education in the context of feminist methodology and reflexivity. When you practise reflective thinking and learning, spirituality comes in." In a similar vein another indicated that "spirituality helps me to become far more reflective as an educator and how I interact with students in that moment of teaching". Another expressed the view: "I bring it into my role as educator, because I ask students how the unseen world/spiritual forces impact on them as a student and in practice. She added that many African students do not see this as dichotomous, because it is part of practice. She argued that this emerged in student profiles and people were denying this in order to fit the dominant discourse. In South Africa, however, we cannot deny that African spirituality influences the population's choice of therapeutic approaches as they rely more on indigenous spiritual methods rather than traditional ones and view a transcendental power as having a major impact on their life (Bhagwan, 2002). The extent to which this form of spirituality is considered at the juncture of practice appears to have been marginalised, considering that students have indicated receiving little education on spirituality (Bhagwan, 2002).

\section{Challenges}

The entire sample expressed that there was a void regarding spirituality in education, supporting findings made in the student survey (Bhagwan, 2010). In the United States, however, spirituality has broken through and transcended barriers (Canda, 2008), as at least 75 Schools of Social Work have begun offering it as an elective (Canda, 2005). Reflecting on the reasons for its neglect in South African pedagogy, one educator said that "there is this misconception that spirituality is not something that you openly discuss. It is about being comfortable enough" to do this. Others expressed the idea that "social work is in search of retaining its professionalism. In a frantic need to be a profession ... we have lost the essence ... 
[and] ... moved away from this direct, intimate caring and the journey of how one connects with another person". Another said, "there is this historical thing that academia is scientific ... it is not about religion". The quest for professionalisation and alignment with the scientific paradigm are the central reasons cited in the literature for the chasm that developed between spirituality and social work in America (Bhagwan, 2002). In fact prior to the inclusion of spirituality in education, American faculty held similar views, saying that spirituality was "fuzzy, unprofessional and inappropriate" (Russel, 1998:23).

Although most educators had offered a rationale for its inclusion in practice and believed it was crucial in education, they maintained that they were "sceptical" and "cautious" about what and how to teach spirituality. One said that the path "would be fraught with difficulties". One reason for this was that "students, and I think educators too, are suspicious of religion because they think you are going to bring in fundamentalist views". Another said, "I think it is important, but I don't know how. There is room to do more and my lack of knowledge has hampered this." These comments reflect a lack awareness of the momentum around spirituality in the American and British contexts (Canda, Nakashima \& Furman, 2004; Gilligan \& Furness, 2006) and a disconnection from the literature which mirrors its salience in education.

The marginalisation of spirituality in South Africa also appears to stem from a relative unease and unpreparedness to bring spirituality into the pedagogical process. This was reflected in the comment: "We must all have a common understanding of what we are talking about", whilst another expressed the view that "this is a difficult one ... there is an element of fear, what does this mean ... how will I cope with this!" "I feel we have a lot to learn about what levels do we do this at, what texts can be recommended and how do we teach this?" Two books by Derezotes, Spiritually Oriented Social Work Practice (2006) and Spiritual Diversity in Social Work Practice (2010), and papers such as "Spirituality: What we can teach and how we can teach it?" (Rothman, 2009), however, are available and can serve as resources to those wishing to knit spirituality into pedagogy. Locally curricula guidelines for spirituality and social work have been designed and can also serve as a resource for those looking to infuse spirituality, where appropriate, into current pedagogy (Bhagwan, 2002).

Despite these fears and anxieties, all the participants except for two concurred on the need to take beginning steps towards bringing spirituality into education. When asked whether spirituality should be a specialised course or offered as an elective, one participant captured the views of most others in saying that "I am not sure whether the present constellation of colleagues would agree with an actual course, they would favour more its integration". The student survey, however, revealed that a majority would like to see a specialised course on spirituality and social work (Bhagwan, 2010). The strong call by students may reflect students' own unpreparedness to deal with spirituality, as well as the needs of clients who may have brought spiritual issues to the helping situation. Given these findings, it is important that some light be cast on incorporating spirituality into pedagogy rather than maintaining its current invisibility. Those educators who favoured mainstreaming it into all content believed that spirituality would provide another lens through which students can help clients, in addition to those theories and models currently being taught. At the juncture of divergent student and educator opinions, the best way forward may be to begin with interweaving it into current education, as suggested by educators. 
Areas for teaching

Participants were also asked what they thought were important components of a course on spirituality and social work. Divergent ideas emerged in the analysis, reflecting the breadth of information that can be infused across all social work modalities. The strongest thread in the data embraced spiritual diversity. Reflecting the views of most participants, one educator said that "I think it should open up that broad canvass of spirituality ... what it means to different people, on different continents, in different cultures, a broad understanding of spirituality and how people construct meaning of it taking into account those different kinds of meaning so that when you engage with social work clients you are aware that their way of thinking, living and acting may be different from your own. You might have ... a set of models, practices ... that may be an imposition." This argument ties up with earlier the discussion that we are not working in the context of African spirituality or the other worldviews embraced by our diverse clientele. Six educators argued for its intertwining with social justice issues, whilst other areas mirrored in the data included history and the charity movements, spiritual interventions, selfawareness and personal growth, ethical issues, the negative facets and spirituality as a resource in therapy. Although these were the broad components identified for a course, a majority of the educators suggested the infusion of these aspects into existing pedagogical processes rather than develop a new course. Even those who articulated potential content areas expressed the importance of gradually building relevant content by saying that "you should open it with an introductory section in first year, and in the second or third year integrate it with practice issues, and with research in the fourth year".

The burgeoning literature synchronises spirituality in areas such as aging, health, assessment and direct practice, death and bereavement, mental health and collaboration with faith organisations (Nelson-Becker \& Canda, 2008), all of which can easily be connected to the South African exit-level outcomes (Lombard, Grobbelaar \& Pruis, 2003). In this vein, Kaplan and Dziegielewski (1999) wrote that practitioners must have an educational preparation to deal with spiritual beliefs, practices and problems with the same level of knowledge and skill as in other practice areas.

American curricula include feminist perspectives, the spiritual roots of the profession, personal growth, functional/dysfunctional aspects of religion and spirituality, diversity, spiritual interventions, collaboration with spiritual organisations, developmental theories of spiritual growth, social justice issues, death and dying, social work values and transpersonal theory (Bhagwan, 2002; Russel, 1998). Viewed holistically, these facets form starting points around which spirituality can be interwoven into current education. Scholars concur on the processes of vertical and horizontal integration into curricula (Derezotes \& Evans, 1995), which indicates that a specialised course is not the primary starting point. Dudley and Helfgott (1990:292) recognised that "the design and teaching of a spirituality course are critical to its success and acceptance by faculty and students". Hence despite societal shifts and student support for spirituality, gradual interweaving, as suggested by this sample, is important to ensuring its acceptance where strong silence has pervaded the field.

\section{Teaching methodologies}

Hodge and Derezotes (2008) contend that, because spirituality content is unique and may differ from other constructs, educators should best teach it through non-traditional pedagogical strategies. Participants in this study favoured this, saying that spirituality should be approached in an "experiential" and "interactive way" with small group discussions. Three educators emphasised facilitating self-awareness and using reflective "individual journaling" to focus on 
diverse spiritual traditions as well as their own. It is only after this, they said, that "students can move to analysing texts and different viewpoints". Several educators argued that a positive teaching context should be created by "making it clear that you do not want to proselytize". One said, "I think there should be an atmosphere of trust and openness ... you should not use indoctrination ... I had one journey when I was teaching diversity issues ... the class shared their belief systems and once a week I gave every group a chance to write a passage about themselves ... there was a sense of awareness that people did things differently, that their symbols and practices may be seen to be weird ... but they are symbolic to the people who perform such rituals ... we developed a sense of acceptance and affirmation of each other's practices".

With regard to themselves, several educators affirmed the need to have a level of comfort in teaching this material. Hodge and Derezotes (2008) said that educators need to model respect for diverse spiritual expressions in their interactions with students, if students were expected to respect spiritual self-determination in practice. Further respect for minority expressions of spirituality would enable these groups to feel comfortable about expressing themselves during classroom discussions, thus creating an inclusive atmosphere that will extend into the realm of practice.

\section{CONCLUSION}

This study was important as it illuminated the position of spirituality in social work pedagogy. While it would appear that a majority of educators in the sample experienced high levels of personal spirituality, spirituality remains on the distant horizon in education. Despite the fact that most participants saw its relevance to education based on the holistic paradigm, very few were able to say that they had given it attention in pedagogy. Where it had received a voice, it would appear that it had surfaced in classroom discussions and was interlinked primarily with diversity. A lack of preparedness and fears regarding its appropriateness, particularly where religion was concerned, seems to have thwarted its ability to grow and connect with other areas in the teaching programme.

Most of the sample believed that the profession could no longer work antithetically to the holistic biopsychosocial-spiritual and environmental paradigm (Derezotes, 2006). Participants identified important areas where interweaving with current teaching can occur, many of which underpin current American spirituality curricula (Bhagwan, 2002). These areas can be the starting points for reflection on beginning to incorporate spirituality gradually into pedagogical processes. Further empirical research will help deepen our understanding of spirituality as it manifests in the lives of our clients and the role it plays in relation to the problems we encounter. It is also important to enquire further about what and how to teach to broaden the scope of what was uncovered in the current study. This study found that spirituality does have a presence in pedagogy; what remains is to determine how educators can work towards threading it into the other dimensions of social work to complete the holistic approach.

\section{REFERENCES}

AMATO-VON-HEMERT, K.A. 1994. Should social work education address religious issues? Yes! Journal of Social Work Education, 30(1):7-11.

BERG, B.L. 2007. Qualitative research methods for the social sciences. Boston: Pearson Education, Inc. 
BHAGWAN, R. 2002. The role of religion and spirituality in social work practice: guidelines for curricula development at South African Schools of Social Work. Durban: University of Natal. (MA Thesis)

BHAGWAN, R. 2007. Tools and techniques to facilitate spiritually sensitive clinical assessment and intervention. The Social Work Practitioner-Researcher, 19(3):25-40.

BHAGWAN, R. 2010. Spirituality in social work: a survey of students at South African universities Social Work Education, 29(2):188-204.

BRAUD, W. \& ANDERSON, R. 1998. Transpersonal research methods for the social sciences. USA: Sage Publications.

BULLIS, R.K. 1996. Spirituality in social work practice. Washington DC: Taylor and Francis.

CANDA, E.R. 2005. Integrating religion and social work in dual degree programs. Journal of Religion and Spirituality in Social Work, 24(1/2):79-91.

CANDA, E.R. 2008. Spiritual connections in social work: boundary violations and transcendence. Journal of Religion and Spirituality in Social Work: Social Thought, 27(12):25-33.

CANDA, E.R. \& FURMAN, L.D. 1999. Spiritual diversity in social work practice: the heart of helping. New York: The Free Press.

CANDA, E.R. \& FURMAN, L.D. 2010. Spiritual diversity in social work practice: the heart of helping $\left(2^{\text {nd }}\right.$ ed $)$. New York: The Free Press.

CANDA, E.R., NAKASHIMA, M. \& FURMAN, L.D. 2004. Ethical considerations about spirituality in social work: Insights from a national qualitative survey. Families in Society, 85(1):27-35.

CARROLL, M.M. 2001. Conceptual models of spirituality. In: CANDA, E.R. \& SMITH, E.D. (eds) Transpersonal perspectives on spirituality in social work. New York: The Haworth Press Inc.

COWLEY, A.S. \& DEREZOTES, D. 1994. Transpersonal psychology and social work education. Journal of Social Work Education, 30(1):1-10.

DEREZOTES, D.S. 2006. Spiritually oriented social work practice. Boston: Pearson Education Inc.

DEREZOTES, D.S. \& EVANS, K.E. 1995. Spirituality and religiosity in practice: in-depth interviews of social work practitioners. Social Thought, 18(1):39-56.

DEY, I. 1999. Grounding grounded theory: guidelines for qualitative inquiry. California: Academic Press.

DUDLEY, J.R. \& HELFGOTT, C. 1990. Exploring a place for spirituality in the social work curriculum. Journal of Social Work Education, 3:287-293.

FAVER, C.A. 1986. Religion, research and social work. Social Thought, 12(3):19-29.

FOUCHÉ, C.B. 2005 Qualitative research designs. In: DE VOS, A.S., STRYDOM, H., FOUCHÉ, C.B. \& DELPORT, C.S.L. (eds.) Research at grassroots - for the social sciences and human service professions. Pretoria: Van Schaik Publishers. 
FOUCHÉ, C.B. \& DELPORT, C.S.L. 2005 Introduction to the research process. In: DE VOS, A.S., STRYDOM, H., FOUCHÉ, C.B. \& DELPORT, C.S.L. (eds) Research at grassroots - for the social sciences and human service professions. Pretoria: Van Schaik Publishers.

GILLIGAN, P. \& FURNESS, S. 2006. The role of religion and spirituality in social work practice: views and experiences of social workers and students. British Journal of Social Work, 36(4):617-637.

HODGE, D.R \& DEREZOTES, D.S. 2008. Postmodernism and spirituality: some pedagogical implications for teaching content on spirituality. Journal of Social Work Education, 44(1):103123.

KAPLAN, A.J. \& DZIEGIELEWSKI, S.F. 1999. Graduate social work students' attitudes and behaviours toward spirituality and religion: issues for education and practice. Social Work and Christianity, 26(1):25-39.

LOEWENBERG, F.M. 1988. Religion and social work practice in contemporary American society. New York: Columbia University Press.

LOMBARD, A., GROBBELAAR, M. \& PRUIS, S. 2003. Standards for social work qualifications in South Africa. Social Work/Maatskaplike Werk, 39(1):1-17.

NELSON-BECKER, H. \& CANDA, E.R. 2008. Spirituality, religion, and aging research in social work: state of the art and future possibilities. Journal of Religion, Spirituality and Aging, 20(3):177-193.

ROTHMAN, J. 2009. Spirituality: what we can teach and how we can teach it? Journal of Religion and Spirituality in Social Work, 28:161-184.

RUSSEL, R. 1998. Spirituality and religion in graduate social work education. Spirituality in Social Work: New Directions, 18(2):15-29.

SALEEBEY, D. 1997. The strengths perspective in social work practice. New York: Longman Publishers.

STRAUSS, A.L. \& CORBIN, J. 1990. Basics of qualitative research: grounded theory procedures and techniques. Newbury Park: Sage Publications.

TOLLIVER, W.G. 1997. Invoking the spirit: a model for incorporating the spiritual dimension of human functioning into social work practice. Smith College Studies in Social Work, 67(3):477-486.

Dr Raisuyah Bhagwan, Department of Community Health Studies, Faculty of Health Sciences, Durban University of Technology, Durban, South Africa. 